Research Article

\title{
TSH screening practice in psychiatric inpatient unit at hmc, in qatar-a quality improvement project
}

Volume 5 Issue 5 - 2016

\section{Background}

The relationship between TSH and psychiatric illness is a well known although understudied field in Psychiatry. In a study done in India by Radhakrishnan et al., ${ }^{1}$ abnormal thyroid hormonal status was found in $29 \%$ of patients with schizophrenia $23.2 \%$ in patients with mood disorders had abnormal TSH. ${ }^{1}$ Meanwhile a study in Poland showed that the prevalence of thyroid dysfunction was higher in mood disorders. ${ }^{2} \mathrm{Hu} \mathrm{LY}$ et al., ${ }^{3}$ explored the relationship of hyperthyroidism and the subsequent development of bipolar disorders and they found that patients with hyperthyroidism were more likely to develop bipolar disorder. ${ }^{3}$ These studies demonstrate the importance of thyroid function in the development of various disorders.

Both the initial presentation and management of various mental health diseases are effected by underlying thyroid illness. How the inadequate thyroid hormone impacts the brain functions and how the treatment effects cognition are not fully understood. Miller et al. ${ }^{4}$ prospectively assessed the effects of thyroid replacement therapy on memory in hypothyroidism, their results revealed an increased verbal memory retrieval in treated hypothyroid patients. This suggests that the memory defects can be reversed with levothyroxine treatment.

Najafi et al., ${ }^{5}$ demonstrated that depressed patients with hypothyroidism showed improvement in the somatic subscale in the intervention group, whilst the affective subscale of Beck Depression Inventory did not show any improvement. Thus we can see that treatment of hypothyroidism effect the patients symptoms differently. ${ }^{5}$

This study is aimed to find the percentage of patients whose TSH was screened upon admission to inpatient psychiatry.

\section{Methods}

This is a retrospective Quality Improvement Project reviewing all the admissions to the impatient unit in the entire year of 2013, a total of 754 admissions. The data was collected using unique patient identification numbers and no personal identifiable data was collected.

\section{Results}

The patient population consisted of 600 male and 154 female patients, aged 17-72. (Table $1 \& 2$ ) $21 \%$ female, grossly reflecting the population distribution in this country where female constitute only $23 \%$ of the population.

434 were screened using TSH level at the time of admission or $57.5 \%$ of all admission; of those tested we found 59patients or $13.6 \%$ with abnormal TSH values. Subsequently, if all patients were to be tested then the projected abnormal results would be 93 patients. So, it leads all to conclude that possible abnormal TSH results among the mentally ill in Qatar is about $12.33 \%$ of all admissions. Which is higher than what Cohen and Swigar showed of $9 \%$ of their admissions. ${ }^{6}$

\author{
Adel S Zaraa, Alaa MTaha, Mahmoud \\ Aborabeh, Mahmoud Midany \\ Department of Psychiatry, Qatar
}

Correspondence: Adel Zaraa, Professor of Clinical Psychiatry, University OUCOM, Ohio, USA, WCMC, HMC, ED, Po Box 3050, Doha, Qatar, Tel 9743347277, Email drzaraa@gmail.com

Received: March 13, 2016 | Published: March 22, 2016

\section{Recommendations and Conclusion}

A wide range of mental disorders are either precipitated or have their course influenced by the Thyroid Status. On one end of the spectrum we find the delirium of hyperthyroidism and the coma of myxedema; ${ }^{7}$ on the other end of the spectrum, we encounter subtle and less dramatic comorbidities like depression and apathy. Research and clinical experience over the past 150years have shown a clear pattern of tight correlation between the level of TSH and numerous Axis I disorders, hence we call for the screening of all psychiatric patients TSH on admission, especially that it may be the only occasion when those patients may stand the chance to receive a comprehensive medical care alongside the psychiatric care.

\section{Acknowledgments}

None.

\section{Conflicts of interest}

Author declares there are no conflicts of interest.

\section{Funding}

None.

\section{References}

1. Radhakrishnan R, Calvin S, Singh JK, et al. Thyroid dysfunction in major psychiatric disorders in a hospital based sample. Indian $\mathrm{J} \mathrm{Med}$ Res . 2013;138(6):888-893.

2. Wysokiński A, Kłoszewska I. Level of thyroid-stimulating hormone (TSH) in patients with acute schizophrenia, unipolar depression or bipolar disorder. Neurochem Res. 2014;39(7):1245-1253.

3. Hu LY, Shen CC, Hu YW, et al. Hyperthyroidism and risk for bipolar disorders: a nationwide population-based study. PLoS One . 2013;8(8):e73057.

4. Miller KJ, Parsons TD, Whybrow PC, et al. Memory improvement with treatment of hypothyroidism. Int J Neurosci. 2006;116(8):895-906. 
5. Najafi L, Malek M, Hadian A, et al. Depressive symptoms in patients with subclinical hypothyroidism--the effect of treatment with levothyroxine: a double-blind randomized clinical trial. Endocr Res. 40(3):121-126.

6. Cohen KL, Swigar ME. Thyroid function screening in psychiatric patients. JAMA. 1979;242(3):254-257.
7. Lishman A. Organic Psychiatry. (2nd edn), Blackwell Scientific, Oxford, England. 1987. 